\title{
Analytical Calculation Method for the Preliminary Analysis of Self-Anchored Suspension Bridges
}

\author{
Shaorui Wang, ${ }^{1}$ Zhixiang Zhou, $^{1,2}$ Yanmei Gao, ${ }^{1}$ and Yayi Huang ${ }^{3}$ \\ ${ }^{1}$ School of Civil Engineering Architecture and Construction, Chongqing Jiaotong University, Chongqing 400074, China \\ ${ }^{2}$ State Key Laboratory Breeding Base of Mountain Bridge and Tunnel Engineering, Chongqing 400074, China \\ ${ }^{3}$ Editorial Department of Applied Mathematics and Mechanics, Chongqing Jiaotong University, Chongqing 400074, China
}

Correspondence should be addressed to Shaorui Wang; ruiruiplace@163.com

Received 20 October 2014; Revised 31 January 2015; Accepted 27 February 2015

Academic Editor: Daniela Boso

Copyright (C) 2015 Shaorui Wang et al. This is an open access article distributed under the Creative Commons Attribution License, which permits unrestricted use, distribution, and reproduction in any medium, provided the original work is properly cited.

\begin{abstract}
The stiffening girder of self-anchored suspension bridge (SSB) is subjected to huge axial force because the main cable is directly anchored on the end of the stiffening girder. To obtain a simple model and accurately understand the mechanical behavior of the whole structure in preliminary design, this paper proposed an analytical calculation method considering the combined effects of the main cable-suspender-stiffening girder. On the basis of the deflection theory of the stiffening girder, the relation between the girder shape and the suspender force was explored. The relation between the main cable end force (MCEF) and the suspender force was derived through segmental catenary theory, and iteration method was further improved to avoid the divergence condition. Finally the solution was obtained through satisfying the compatibility condition. The proposed method does not need to iterate manually and can save calculation time. Examples are introduced to verify the applicability of this method, with the result that this method considers the combined effects of the main cable-suspender-stiffening girder, and the finished bridge state satisfies the minimum strain energy of the stiffening girder. Results also indicate that this method has fast convergence speed and high precision.
\end{abstract}

\section{Introduction}

In the early years (1801-1870), the spans of suspension bridge (SB) were relatively small and the main cables were relatively light, so linear-elastic theories are usually used to study the mechanical behavior of the whole structure. Because the nonlinearity of the main cable and suspender is growing with the increase of the span length, the deflection theory is put forward and rsearchers have done so afterwards. Steinman [1] introduced the traditional analytical method of SB represented by the so-called deflection theory; Jennings [2] modified the deflection theory allowing it for the structural behavior of suspension bridges in which the deck is supported by two or more cables with different profiles; Wollmann [3] presented a practical method for the preliminary analysis of suspension bridges based on the deflection theory. Ohshima et al. [4] presented a practical analysis of a suspension bridge under vertical loads by means of the stiffness matrix method. With the development of computer technology, modern suspension bridges are typically analyzed by using computer programs with nonlinear analysis capabilities based on finiteelement formulations. Jung et al. [5] presented a nonlinear analysis method based on the unstrained element length for determining initial shape of suspension bridges under dead loads. Montoya et al. [6] presented a new methodology to determine the safety of suspension bridge main cables. The approach is the first one incorporating a finite-element (FE) model to predict the cable's failure load, which can account for the load recovery due to friction in broken wires and simulate the reduced cable's strength as a three-dimensional random field.

The finite-element theory was also applied in selfanchored suspension bridges (SSB). Kim et al. $[7,8]$ proposed a nonlinear shape-finding analysis for a self-anchored suspension bridge. The procedure consists of two successive steps of nonlinear analysis. The first step is for the cable-only system and the second for the total bridge system. In the second step, the fixed boundary of the anchor points of the main cables and hangers treated in first step must be changed manually, which is burdensome. 
Such models based on finite-element theory may have thousands of degrees of freedom. So there is a need for simpler models to better understand the structural behavior in a way not offered by finite-element analysis. Such models are useful for the preliminary design and independent checks of more complex models. And many scholars have been exploring such models.

Tan [9], based on the analysis of finite displacement theory and analytical iteration method, proposed a determination method of the reasonable finished bridge state of SSB considering the main cable alignment, the force of suspender, and the stiffening girder; Han et al. [10] studied the main cable shape-finding method of SSB with spatial cables. Li et al. [11], based on the reasonable internal force requirements of SSB main cable and the suspender, put forward a determination method of the reasonable suspender force of SSB, and this method considered the effect of stiffening girder alignment through finite-element method, but it is relatively complicated because the finite-element analysis procedure must be iterated manually.

In summary, so far the analysis method of SSB mainly includes (1) linear-elastic theory and deflection theory; (2) finite displacement theory; (3) finite-element theory; (4) combined method based on finite-element theory and the numerical analytical method. Methods (1) and (2) are effective methods in the early stage, but they have many assumptions and are only suitable for some small span bridges. These two methods are barely used now. Method (3) reduces the assumptions and the calculation result meets the actual circs better. However, the method needs a model with thousands of degrees of freedom, and the model is complex. The fixed boundary also needs to be changed manually in the second step of Method (3), and the calculation time is very long. In Method (4), the main cable is considered through the numerical analytical method, and the stiffening girder is considered through finite-element method. The method is a more accurate calculation for main cable, but the analysis procedure must be iterated manually, which is time-consuming.

So this paper proposes an analytical calculation method considering the combined effect of the main cable-suspenderstiffening girder. Compared to the above mentioned methods, in the method, the main cable and the stiffening girder are all considered through the numerical analytical method; then the calculation procedure has no need to iterate manually, which can save calculation time.

The method also can quickly and effectively find the reasonable finished bridge state of SSB and help designers to better understand the structural behavior in a manner offered by a simpler and accurate model.

The paper is organized as follows. Section 2 briefly presents the principle of the proposed method. Sections 35 are dedicated to the main cable analysis, the stiffening girder analysis, and the deformation compatibility condition of the calculation model, respectively. Section 6 introduces the numerical calculation process of the proposed method. Examples are provided in Section 7 to illustrate the application of the method. Finally, Section 8 summarizes the findings of this paper and presents some conclusions.

\section{The Principle of the Proposed Method}

Self-anchored suspension bridge is a high-order statically indeterminate structure; thus the direct calculation has certain difficulties. In the proposed method, one model is established, which includes three parts, namely, the main cable, the stiffening girder, and the deformation compatibility condition. The main cable and the stiffening girder are analyzed independently, and then they are coupled by the deformation compatibility condition. The discrete graph of SSB is shown in Figure 1.

As to Part I of the calculation model, the stiffening girder is assumed as a simply supported girder along the whole bridge. The shape of the stiffening girder (SSG) needs to be given firstly, and then calculate the suspender force (SF). The scheme of calculation principle is shown in Figure 2.

The support of pylon to the stiffening girder is replaced as concentrate forces. The counterweights set at the pylon-girder joint and girder end can also be assumed as concentrate forces at supports, and they have slight influence upon the internal force of the stiffening girder. The MCEF (the main cable end force) eccentrically acts upon the stiffening girder, and, through axis shift formula, it can be divided into a horizontal force acting on the neutral axis of stiffening girder and an additional bending moment $M^{1}$ as shown in Figure 1.

As to Part II of the calculation model, the main cable, SF can be given from Part I, and calculate the MCEF satisfying the rise to span ratio and other requirements.

On the basis of deflection theory and the principle of minimum strain energy of the stiffening girder, the SF and MCEF given from Part I and II are substituted into Part III of the calculation model, the deformation compatibility condition, and finally check whether the SF and MCEF satisfy the criterion (the displacements at hanging point equal zero), if they do, the calculation stops; otherwise, modify the SF and repeat the iteration.

When the error of SSG meets the convergence condition of precision requirement, the iteration stops and the last calculation is the expected result.

For SSB with overhanging span, the bearing reaction $R$ and the self-weight of anchor span $G$ can be equivalent to additional moment $M^{2}$ and concentrated force $G-R$ acting on the end of anchor section, as shown in Figure 1. The influence of shrinkage and creep of concrete pylon to the alignment can be considered by a reduction of the pylon height. And more information could be found in relative references.

\section{Part I of Calculation Model: The Stiffening Girder Analysis}

Under the condition of the known SSG (the shape of the stiffening girder), Part I is used to calculate SF (the suspender force). The calculation procedure needs to iterate and the influential matrix $B$ of SSG to SF should be obtained.

3.1. The Control Principle of SSG. The reasonable finished bridge state of SSB is measured by the stress state of the stiffening girders under dead load. Furthermore, reasonable 


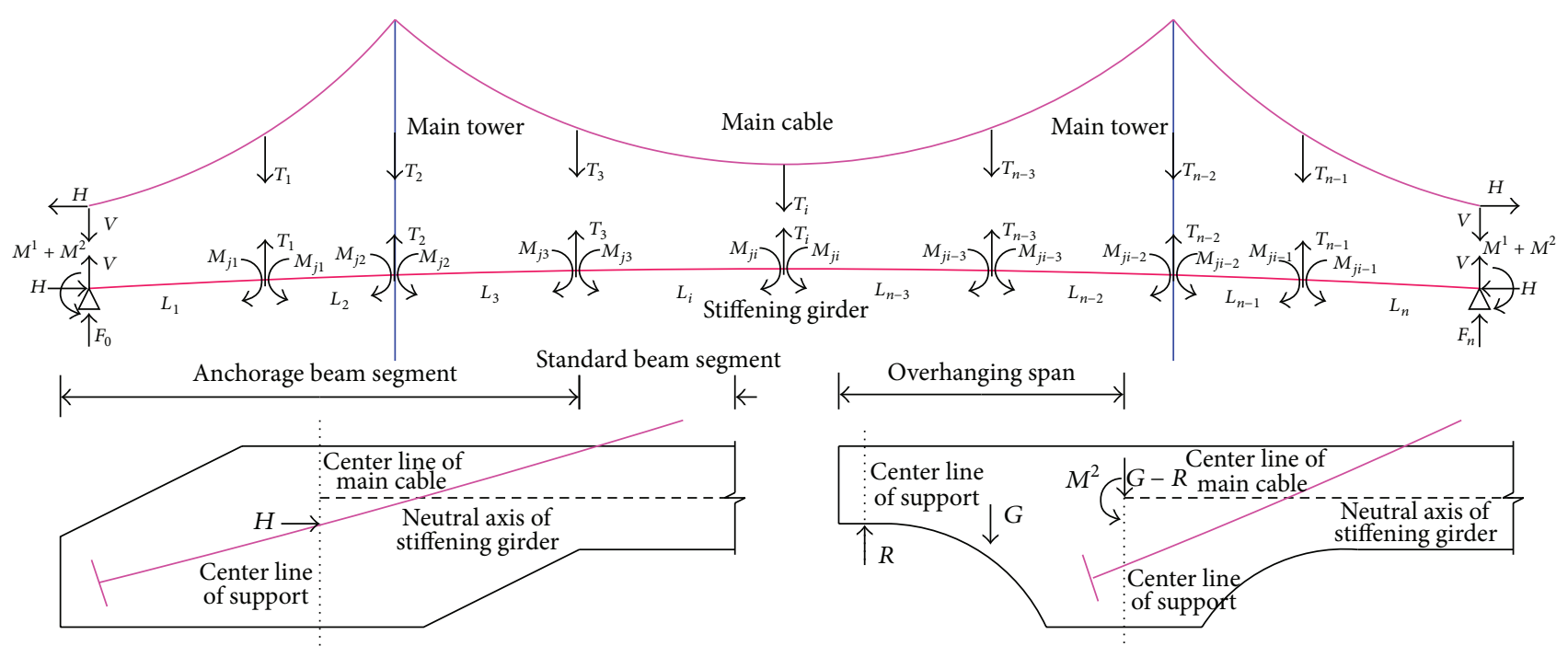

FIGURE 1: The discrete graph of SSB.

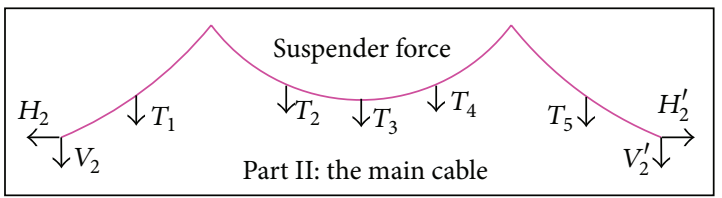

Meet the shape requirements of the stiffening girder; calculate the suspender force $T_{i}$

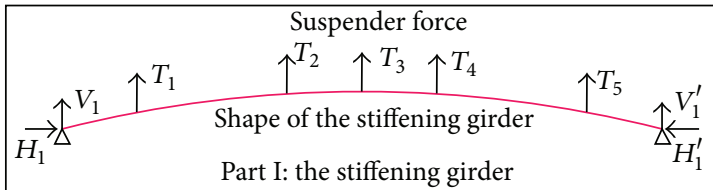

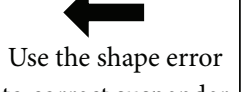
to correct suspender force $T_{i}$
Meet the shape requirements of the main cable; calculate the reaction forces $\mathrm{H}_{2}$ and $V_{2}$

Figure 2: The scheme of the calculation principle.

stiffening stress state can be ensured through the reasonable suspender force, which can be solved by rigid supported continuous beam method, zero displacement method, or minimum bending energy method. The solving process using minimum bending energy method is described as follows.

The structural cost can be measured by bending strain energy; thus the smaller the bending strain energy is, the less the materials the structure costs. The bending strain energy of the stiffening girder can be obtained through

$$
U=\frac{1}{2} \int_{s} \frac{M^{2}}{E I} d s .
$$

According to the principle of minimum bending energy, $U$ (bending energy) should meet the following relationship:

$$
\frac{\partial U}{\partial X_{i}}=0
$$

where $X_{i}$ means the suspender force.
Actually, the physical meanings of rigid supported continuous beam method, zero displacement method, and minimum bending energy method are the same as described as (2); that is, the vertical displacement of the suspending point is zero under the joint action of suspender force, the horizontal component of the main cable, and the dead load.

3.2. Impact Analysis of SSG to SF. To complete nonlinear analysis of the stiffening girder, the following two assumptions are made.

(i) Neglect the influences of the shear deformation on the alignment of the stiffening girder.

(ii) Neglect the influences of the axial deformation on the alignment of the stiffening girder.

Hence, the alignment of the stiffening girder is only related to the bending moment.

As shown in Figure 3, $q$ means the uniformly distributed load of stiffening girder self-weight, $L_{i}$ means the length of 


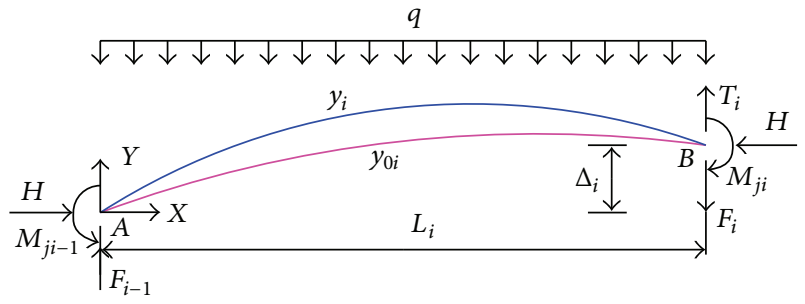

FIGURE 3: The calculation diagram of the girder segment.

girder segment, $H$ means the horizontal end reaction of the main cable, $M_{j i}$ means the bending moment at the hanging point, $F_{i}$ means the shearing force of girder, $T_{i}$ means the suspender force, and $y_{i}$ means the alignment of the girder segment under the joint action of the suspender tension force, the horizontal component of the main cable, and the constant load. $y_{0 i}$ is the initial camber of the stiffening girder which can meet the precision requirements using designed alignment in calculation. The starting point of the girder segment is assumed as the origin point.

According to (2), the stress state of the girder end under uniformly distributed load $q$ meets equilibrium equation when ensuring that no vertical displacement occurs in points $A$ and $B$ :

$$
\begin{gathered}
F_{i}=F_{i-1}+T_{i}-q L_{i} \\
M_{j i}=\frac{q L_{i}^{2}}{2}-F_{i-1} L_{i}+M_{j i-1}+H \Delta_{i}+M^{\prime} \\
M_{i}=\frac{q x^{2}}{2}-F_{i-1} x+M_{j i-1}+H y \\
\Delta_{i}=y_{i}-y_{i-1} .
\end{gathered}
$$

Neglecting the shearing deformation, the equation can be described as follows:

$$
\frac{M_{i}}{E I}=-\left(\frac{y_{i}^{\prime \prime}}{\left(1+y_{i}^{\prime 2}\right)^{3 / 2}}-\frac{y_{0 i}^{\prime \prime}}{\left(1+y_{0 i}^{\prime 2}\right)^{3 / 2}}\right) .
$$

From (3), deflection differential equilibrium equation can be obtained:

$$
y_{i}^{\prime \prime}+\frac{H}{E I} y_{i}=\frac{-q}{2 E I} x^{2}+\frac{F_{i-1}}{E I} x-\frac{M_{j i-1}}{E I}+y_{0 i}^{\prime \prime} .
$$

In the equation, assume

$$
\begin{array}{cc}
A^{2}=\frac{H}{E I} ; & B=\frac{-q}{2 E I} ; \\
C_{i}=\frac{F_{i-1}}{E I} ; & D_{i}=-\frac{M_{j i-1}}{E I} .
\end{array}
$$

Because $y_{0 i}$ is a continuous function, we can spread out power series at $x=0$ to conveniently solve the differential equation:

$$
y_{0 i}=\sum_{m=0}^{\infty} G_{m}^{i} x^{m}
$$

where $G_{m}^{i}=y_{0 i}^{(m)}(0) / m$ !
In practical calculation, when $m=4$, the result can meet the precision requirement:

$$
\begin{aligned}
& y_{0 i}=\sum_{m=0}^{4} G_{m}^{i} x^{m} \\
& =G_{0}^{i}+G_{1}^{i} x+G_{2}^{i} x^{2}+G_{3}^{i} x^{3}+G_{4}^{i} x^{4}, \\
& y_{0 i}^{\prime \prime}=2 G_{2}^{i}+6 G_{3}^{i} x+12 G_{4}^{i} x^{2} \text {. }
\end{aligned}
$$

Substitute (9) into the differential equation (4):

$$
\begin{aligned}
y_{i}= & E_{1 i} \sin (A x)+E_{2 i} \cos (A x) \\
& +\frac{\left(B x^{2}+C_{i} x+D_{i}\right) A^{2}-2 B}{A^{4}} \\
& +\frac{\left(2 G_{2}^{i}+6 G_{3}^{i} x+12 G_{4}^{i} x^{2}\right) A^{2}-24 G_{4}^{i}}{A^{4}} .
\end{aligned}
$$

Equation (10) is the deflection equation of the girder segment considering geometrical nonlinearity. With the known quantities $A, B, C_{i}, D_{i}, G_{2}^{i}, G_{3}^{i}$, and $G_{4}^{i}$ and combining with the controlling condition of the minimum strain energy of the stiffening girder, $y_{i}(0)=0, y_{i}\left(L_{i}\right)=\Delta_{i}$, the expressions of $E_{1 i}, E_{2 i}$ are given by

$$
\begin{aligned}
E_{1 i}= & \frac{\Delta_{i}}{\sin \left(A L_{i}\right)}-E_{2 i} \operatorname{ctan}\left(A L_{i}\right) \\
& -\frac{\left(B L_{i}^{2}+C_{i} L_{i}+D_{i}\right) A^{2}-2 B}{A^{4} \sin \left(A L_{i}\right)} \\
& -\frac{\left(2 G_{2}^{i}+6 G_{3}^{i} L_{i}+12 G_{4}^{i} L_{i}^{2}\right) A^{2}-24 G_{4}^{i}}{A^{4} \sin \left(A L_{i}\right)} \\
E_{2 i}= & \frac{2 B}{A^{4}}-\frac{D_{i}}{A^{2}}+\frac{24 G_{4}^{i}}{A^{4}}-\frac{2 G_{2}^{i}}{A^{2}} .
\end{aligned}
$$

For each girder segment, its deflection equation that meets the minimum stain energy theory can be obtained with known $T_{i}$ and $H$. Besides, the deflection equation should also satisfy the compatibility condition of the stiffening girder; thus

$$
\delta_{i}=y_{i+1}^{\prime}(0)-y_{i}^{\prime}\left(L_{i}\right)=0 .
$$

Then differentiate (12):

$$
d \delta_{i}=d y_{i+1}^{\prime}(0)-d y_{i}^{\prime}\left(L_{i}\right)=0 \text {. }
$$


In (13), $T_{i}$ is unknown, and differentiate $y_{i}^{\prime}$ :

$$
\begin{aligned}
d y_{i+1}^{\prime}(0)= & \frac{\sin \left(A L_{i+1}\right)-A L_{i+1}}{A^{2} \sin \left(A L_{i+1}\right)} \sum_{j=1}^{n-1} \frac{\partial C_{i+1}}{\partial T_{j}} d T_{j} \\
& +\frac{\cos \left(A L_{i+1}\right)-1}{A \sin \left(A L_{i+1}\right)} \sum_{j=1}^{n-1} \frac{\partial D_{i+1}}{\partial T_{j}} d T_{j} \\
d y_{i}^{\prime}\left(L_{i}\right)= & \left(\frac{1}{A^{2}}-\frac{\operatorname{ctan}\left(A L_{i}\right)}{A} L_{i}\right) \sum_{j=1}^{n-1} \frac{\partial C_{i}}{\partial T_{j}} d T_{j} \\
+ & \frac{1-\cos \left(A L_{i}\right)}{A \sin \left(A L_{i}\right)} \sum_{j=1}^{n-1} \frac{\partial D_{i}}{\partial T_{j}} d T_{j} \\
d \delta= & d y_{i+1}^{\prime}(0)-d y_{i}^{\prime}\left(L_{i}\right) \\
= & \frac{\cos \left(A L_{i+1}\right)-1}{A \sin \left(A L_{i+1}\right)} \sum_{j=1}^{n-1} \frac{\partial D_{i+1}}{\partial T_{j}} \\
& -\frac{1-\cos \left(A L_{i}\right)}{A \sin \left(A L_{i}\right)} \sum_{j=1}^{n-1} \frac{\partial D_{i}}{\partial T_{j}} d T_{j} \\
& +\left(\frac{\sin \left(A L_{i+1}\right)-A L_{i+1}}{A^{2} \sin \left(A L_{i+1}\right)} * \sum_{j=1}^{n-1} \frac{\partial C_{i+1}}{\partial T_{j}}\right. \\
& \left.\quad-\left(\frac{1}{A^{2}}-\frac{\operatorname{ctan}\left(A L_{i}\right)}{A} L_{i}\right) \sum_{j=1}^{n-1} \frac{\partial C_{i}}{\partial T_{j}}\right) d T_{j} .
\end{aligned}
$$

Transform (14) into matrix form:

$$
\begin{gathered}
d \delta=K d T \\
d T=K^{-1} d \delta,
\end{gathered}
$$

where

$$
\begin{gathered}
B=K^{-1} \quad r \quad d T=\left[\begin{array}{c}
d T_{1} \\
\vdots \\
d T_{n-1}
\end{array}\right] \\
K=\left[\begin{array}{ccc}
K_{11} & \cdots & K_{1 n-1} \\
\vdots & \ddots & \vdots \\
K_{n-11} & \cdots & K_{n-1 n-1}
\end{array}\right] \quad d \delta=\left[\begin{array}{c}
\delta_{1} \\
\vdots \\
\delta_{n-1}
\end{array}\right] \\
K_{i j}=\frac{\sin \left(A L_{i+1}\right)-A L_{i+1}}{A^{2} \sin \left(A L_{i+1}\right)} \frac{\partial C_{i+1}}{\partial T_{j}} \\
+\frac{\cos \left(A L_{i+1}\right)-1}{A \sin \left(A L_{i+1}\right)} \frac{\partial D_{i+1}}{\partial T_{j}} \\
-\left(\frac{1}{A^{2}}-\frac{c \operatorname{ctan}\left(A L_{i}\right)}{A} L_{i}\right) \frac{\partial C_{i}}{\partial T_{j}}-\frac{1-\cos \left(A L_{i}\right)}{A \sin \left(A L_{i}\right)} \frac{\partial D_{i}}{\partial T_{j}} .
\end{gathered}
$$

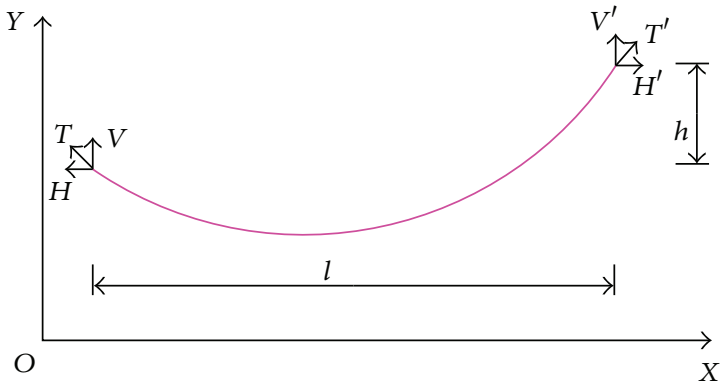

Figure 4: The calculation scheme of the main cable segment.

Matrix $B$ is the influential matrix of SSG to SF, which represents the relationship between $d \delta$ (the first derivate increment of the stiffening girder shape) and $d T$ (the change of suspender force). $d T$ can be solved out through known girder shape and then modify $T(i)$ to adjust the suspender force.

\section{Part II of Calculation Model: The Main Cable Analysis}

Under the condition of the known SF, calculated from Part I, Part II is used to calculate MCEF, which satisfies the shape requirements of main cable by shape-finding.

4.1. The Segmental Catenary Theory of Main Cable. For the SSB, the segmental catenary method assumes that the alignment of the main cable is a catenary, which is more approximate with the actual situation. In the main cable calculation, the segmental catenary method is adopted [12-19].

According to the differential equilibrium equations, geometrical equations, and the physical equations of cable segment, the relation between the shape and the internal force of cable segment is obtained. The calculation scheme is shown in Figure 4:

$$
\begin{aligned}
l= & -\frac{H S_{0}}{E A}-\frac{H}{q}\left\{\ln \left(V+\sqrt{H^{2}+V^{2}}\right)\right. \\
& \left.\quad-\ln \left(V-q S_{0}+\sqrt{H^{2}+\left(V-q S_{0}\right)^{2}}\right)\right\}, \\
h= & \frac{q S_{0}^{2}-2 V S_{0}}{2 E A} \\
& -\frac{1}{q}\left[\sqrt{H^{2}+V^{2}}-\sqrt{H^{2}+\left(V-q S_{0}\right)^{2}}\right] .
\end{aligned}
$$

In formulas (17), $q$ represents the self-weight of the unstressed main cable, $E$ represents the elastic modulus, $A$ represents the cross-sectional area, $l$ represents the span length of the cable segment, $h$ represents the elevation difference of two ends, and $S_{0}$ represents the unstressed length of cable segment. $H$ and $V$ represent the horizontal and vertical component of cable segment force in the left end. 
The calculation process of the main cable alignment is as follows: assume the value of $H$ and $V$ and calculate $S_{0}, l$, and $h$ of each cable segment according to the calculated suspender force, and then check whether the result meets the alignment requirements or not. If it does, calculation stops; otherwise modify the value of $H$ and $V$ and repeat the above steps till the result meets the shape requirements.

\subsection{Improved E-M Iteration Method for the Main Cable Shape-} Finding in the Middle Span. Formulas (17) are nonlinear equations; to solve the equations, the value of $H$ and $V$ should be assumed to get $S_{0}$, and then check whether $h$ of the target point meets the requirements or not. The solving process is an iterative process.

The numerical iterative methods of the main cable in the middle span of SB may not converge in some cases. The main reason is that, in the iteration process, the elevation requirements of end points and intermediate points are considered independently, so that the mutual influences between them are ignored. The proposed E-M iteration method considered the elevation requirements of both the ending points and intermediate points; besides, when modifying the horizontal force $H$ and vertical force $V$, the influences of ending points elevation error $d y_{e}$ and intermediate points elevation error $d y_{m}$ are considered.

As shown in Figure 5, for any Point $A$ on the cable segment, according to the equilibrium equation of moment,

$$
V m-\sum_{i=1}^{n}\left(T_{i} D_{i}+S_{i} w C_{i}\right)-H y=0,
$$

where $H$ and $V$ represent the horizontal and vertical components of the cable segment force in the left end, $T_{i}$ represents the suspender force, $S_{i}$ represents the unstressed length of cable segment, $C_{i}$ represents the distance from the gravity center of cable segment to Point $A, D_{i}$ represents the distance from hanging point to Point $A, y$ and $m$ represent the horizontal and vertical distances from the left ending point of the main cable to Point $A$, respectively, $y_{e}$ and $y_{m}$ represent the elevation of the ending point and the middle point, respectively, and $w$ represents the self-weight of the main cable.

Formula (18) can be transformed into

$$
y=\frac{\left(V m-\sum_{i=1}^{n}\left(T_{i} D_{i}+S_{i} w C_{i}\right)\right)}{H},
$$

where $y$ is a function of $H$ and $V$, and the differential of $y$ is given by

$$
d y=\frac{\sum_{i=1}^{n}\left(T_{i} D_{i}+S_{i} w C_{i}\right)-V m}{H^{2}} d H+\frac{m}{H} d V .
$$

Substitute formula (19) into (20):

$$
d y=-\frac{y}{H} d H+\frac{m}{H} d V
$$

For the ending point, $y=y_{e}, m=L$, then

$$
d y_{e}=-\frac{y_{e}}{H} d H+\frac{L}{H} d V,
$$

where $L$ is the span length of the cable segment.

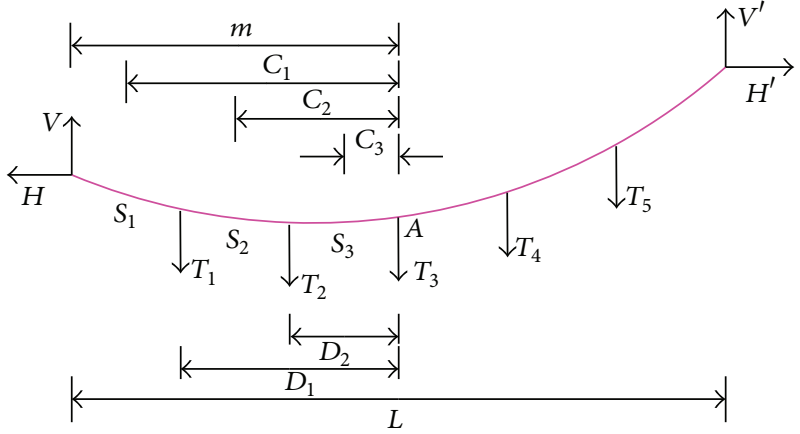

FIgURE 5: The calculation scheme of the E-M method.

For the middle point, $y_{m}=f$, then

$$
d y_{m}=-\frac{f}{H} d H+\frac{m}{H} d V,
$$

where $f$ is the sag of the main cable at the middle point.

Based on formulas (22)-(23), considering the elevation error of the ending and middle points, $H$ and $V$ are modified:

$$
\left[\begin{array}{l}
d y_{e} \\
d y_{m}
\end{array}\right]=\left[\begin{array}{cc}
-\frac{y_{e}}{H} & \frac{L}{H} \\
-\frac{f}{H} & \frac{m}{H}
\end{array}\right]\left[\begin{array}{l}
d H \\
d V
\end{array}\right] .
$$

Then

$$
\left[\begin{array}{l}
d H \\
d V
\end{array}\right]=\frac{H^{2}}{f L-y_{e} m}\left[\begin{array}{cr}
\frac{m}{H} & -\frac{L}{H} \\
\frac{f}{H} & -\frac{y_{e}}{H}
\end{array}\right]\left[\begin{array}{l}
d y_{e} \\
d y_{m}
\end{array}\right] .
$$

For a three-span SB, elevations of two pylons are equal and the middle point is at the mid-span of the intermediate span, where $y_{e}=0, y_{m}=f, m=L / 2$, and then formula (25) can be simplified as

$$
\left[\begin{array}{l}
d H \\
d V
\end{array}\right]=\left[\begin{array}{cc}
\frac{H}{2 f} & -\frac{H}{f} \\
\frac{H}{L} & 0
\end{array}\right]\left[\begin{array}{l}
d y_{e} \\
d y_{m}
\end{array}\right],
$$

where $d y_{e}=0-y_{e}, d y_{m}=f-y_{m}$,

$$
f\left(H_{0}, V_{0}, S_{1}\right)=0
$$

$$
\begin{aligned}
f & \left(H_{i-1}, V_{i-1}, S_{i}\right) \\
= & -\frac{H_{i-1} S_{i}}{E A}-\frac{H_{i-1}}{q} \\
& \cdot\left\{\ln \left(V_{i-1}+\sqrt{{H_{i-1}}^{2}+{V_{i-1}}^{2}}\right)\right. \\
& \left.\quad-\ln \left(V_{i-1}-q S_{i}+{\left.\sqrt{{H_{i-1}}^{2}+\left(V_{i-1}-q S_{i}\right.}\right)^{2}}^{2}\right)\right\}-l_{i}=0
\end{aligned}
$$

$$
f\left(H_{n-1}, V_{n-1}, S_{n}\right)=0
$$




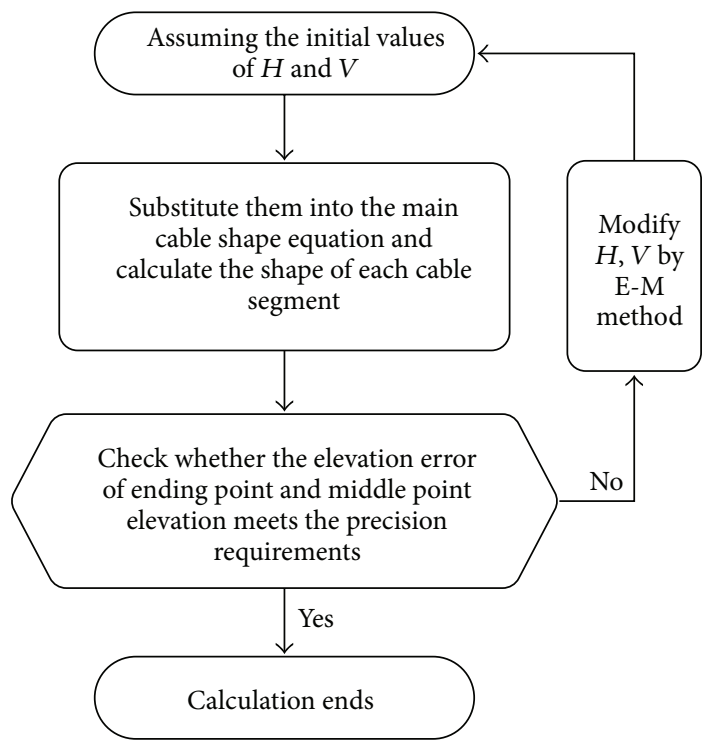

Figure 6: The calculation step of the E-M method.

$$
\begin{gathered}
V l-\sum_{i=1}^{n}\left(G_{i} D_{i}+S_{i} w C_{i}\right)-H y_{m}=0 \\
V L-\sum_{i=1}^{n}\left(G_{i} D_{i}+S_{i} w C_{i}\right)-H y_{e}=0 .
\end{gathered}
$$

E-M iteration method is to solve the nonlinear equations (27) and (28) to obtain the numerical solution. For formula (27), Newton method is used to calculate the elevation of the target point; then substitute the elevation error into (28) and modify $H$ and $V$; finally substitute the modified $H$ and $V$ into (27) to do the new round of iteration. The steps are as follows.

(i) Assume the values of $H$ and $V$ and substitute them into the main cable shape equation, and calculate the shape of each cable segment through Newton iteration method.

(ii) Check whether the elevation error of ending point and middle point elevation meet the precision requirements $\left(\left|d y_{e}\right|<C\right.$ and $\left.\left|d y_{m}\right|<D\right)$; if so, the calculation ends; otherwise, execute step (3).

(iii) Modify $H, V$ through E-M method, and then substitute the modified $H$ and $V$ into step (1). The flow chart is shown in Figure 6.

4.3. The Main Cable Shape-Finding in the Side Span. For the main cable in the side span of SB, the shape-finding can also use formulas (17). Unlike in the middle span, $H$ is known and equals the horizontal component of the main reaction in the middle span, and, in the iteration process, $H$ remains constant and only modifies $V$ as shown in Figure 7. Many scholars have done research on this method; then there is no more discussion here.

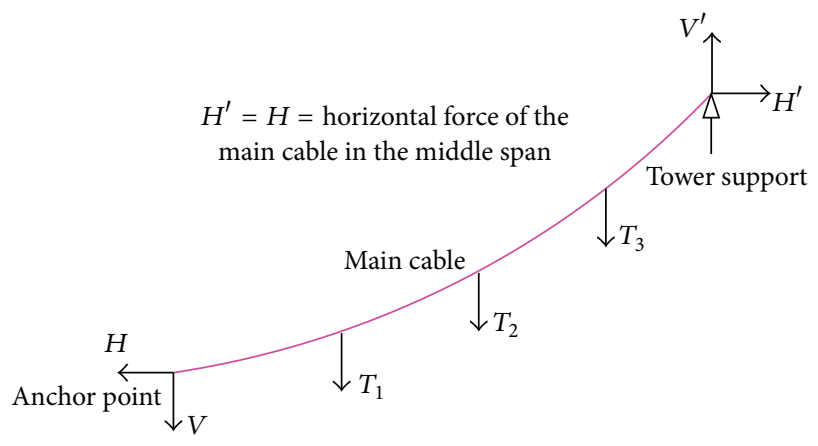

Figure 7: The calculation scheme of the main cable shape-finding in the side span.

\section{Part III of Calculation Model: The Deformation Compatibility Condition}

In Part III, SF and MCEF are substituted into the stiffening equation and check whether the SF and MCEF satisfies the SSG; if it does, the calculation stops, and the last calculation is the expected result; otherwise, modify the SF by matrix $B$ (Section 3.2) and repeat the iteration process.

\section{The Numerical Calculation Process of the Proposed Method}

According to the theories introduced before, an analytical calculation method considering the combined effect of the main cable-suspender-stiffening girder is programmed by VB programing language. The main steps are as follows.

(i) Under the condition of the known SSG (the shape of the stiffening girder), calculate the suspender force $T_{0}(i)$ according to the known girder segments $N$, segment length $L(i)$, elastic modulus $E$, cross-sectional moment of inertia $I$, uniform load $q$, design shape equation of the stiffening girder $y_{0 i}$, and the error precision requirement $e$.

(ii) With the suspender force $T_{0}(i)$, solve out the horizontal force $\mathrm{H}_{0}$ of the stiffening girder end.

(iii) Substitute $H_{0}$ and $T_{0}(i)$ into the equation of the stiffening girder; then the influence matrix $B, d \delta$, and $d T$ can be obtained.

(iv) Check whether $|d \delta|$ meets the precision requirements or not; if $|d \delta|<e$, the calculation ends; otherwise modify $T_{0}(i)\left(T_{0}(i)=T_{0}(i)+d T\right)$ until $|d \delta|$ meet the precision requirements.

(v) Substitute the new $T_{0}(i)$ into step (ii); repeat steps (ii) to (iv).

The flow chart is shown in Figure 8.

\section{Example Analysis}

7.1. Example of the Proposed Method. Figure 9 is the general layout of a self-anchored suspension bridge with the span 
TABle 1: The suspender force in each iteration step.

\begin{tabular}{lcccccccccc}
\hline Iteration times & \multicolumn{1}{c}{ Suspender number } & \multicolumn{4}{c}{ Horizontal reaction of the main cable } \\
& 1 & 6 & 10 & $T_{1}$ & 12 & 17 & 22 & 26 & $H$ & 30000.0 \\
\hline 0 & 2119.6 & 1781.7 & 1813.2 & 1865.1 & 1813.2 & 1783.0 & 1736.8 & 1737.4 & $|\Delta H / H|$ \\
1 & 2119.6 & 1781.7 & 1813.2 & 1865.1 & 1813.2 & 1782.8 & 1721.5 & 1722.2 & 40666.3 & $2.62 E-01$ \\
2 & 2119.6 & 1781.7 & 1813.2 & 1865.1 & 1813.2 & 1782.8 & 1721.8 & 1722.5 & 40428.7 & $5.88 E-03$ \\
3 & 2119.6 & 1781.7 & 1813.2 & 1865.1 & 1813.2 & 1782.8 & 1721.8 & 1722.5 & 40434.0 & $1.31 E-04$ \\
4 & 1790.0 & 1792.4 & 1784.3 & 1779.9 & 1781.6 & 1772.3 & 1764.0 & 1767.7 & 40433.8 & $4.95 E-06$ \\
\hline
\end{tabular}

arrangement of $150 \mathrm{~m}+406 \mathrm{~m}+150 \mathrm{~m}$. The suspender spacing arrangement in the side span is $14.5+9 \times 13.5+14$ and is $14+28 \times 13.5+14$ in the middle span. The theoretical vertex of the main cable is $85 \mathrm{~m}$ higher than the theoretical anchorage point. For the stiffening girder, the moment of inertia is $I=4.428675 \mathrm{~m}^{4}$, the elastic modulus is $E=$ 2.1E05 MPa, and the dead load in the first and second phase is $q=132 \mathrm{kN} / \mathrm{m}$; for the main cable, the cross-sectional area is $A=0.1038 \mathrm{~m}^{2}$, elastic modulus is $E=1.95 E 05 \mathrm{MPa}$, the self-weight is $q=8.145 \mathrm{kN} / \mathrm{m}$, and the ratio of rise to span is $f / L=1 / 5.8$. To simplify the calculation, ignoring the selfweight of the clamp and suspender, neglecting the main cable and saddle modification, the calculation is just based on the theoretical vertex of the main cable, assuming that the left anchorage of main cable is as the coordinate origin, as shown in Figure 9.

The stiffening girder linear is designed with a two-way longitudinal slope of $1 \%$ and a round curve transition of $R=$ $9450 \mathrm{~m}$ in the middle (Figure 10).

As shown in Table 1 and Figure 11, the results of the proposed method can meet the precision requirements $(\delta=$ $\Delta H / H<10^{-5}$ ) with fast convergence rate (4 times of iteration). And the final suspender force is more even with the maximum of $2119.6 \mathrm{kN}$ in $1 \#$ and $51 \#$ suspender.

Figure 12 indicates that the calculated main cable shape in this method is smooth without any mutation point and it also satisfies the requirement of rise to span ratio of the middle $\operatorname{span}(f / L=1 / 5.8)$.

Figure 13 shows that the bending moment of the stiffening girder is distributed uniformly, with the maximum positive and negative bending moment of $2823.6 \mathrm{KN} \cdot \mathrm{m}$ and $2057.3 \mathrm{kN} \cdot \mathrm{m}$, respectively, which occur near to the end of the stiffening girder.

7.2. Example of the E-M Method in Part II. Figure 14 is the general layout of a main cable in the middle span. The crosssectional area is $A=0.1038 \mathrm{~m}^{2}$, elastic modulus is $E=$ $1.95 E 05 \mathrm{MPa}$, the self-weight is $q=8.145 \mathrm{kN} / \mathrm{m}$, and the ratio of rise to span is $f / L=1 / 5.8$. To simplify the calculation, ignoring the self-weight of the clamp and suspender, the calculation just assumes the left anchorage of the main cable as the coordinate origin (Figure 14).

Two examples are presented and compared to verify the convergence of E-M method as follows.

(i) In example 1, the suspender forces are distributed evenly and symmetrically, with the value of mainly around $1800 \mathrm{kN}$, as shown in Table 2.

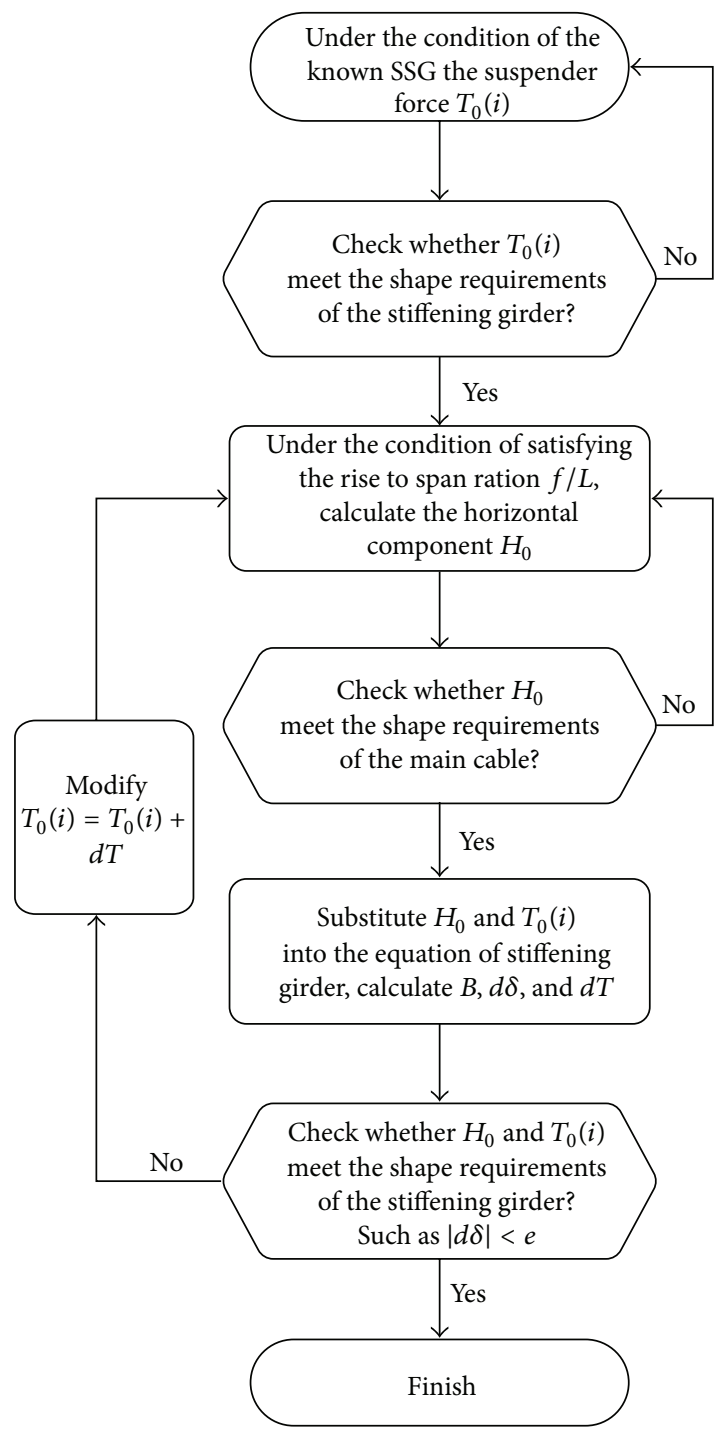

Figure 8: The flow chart.

Table 3 shows that, after 7 times of iteration, the end point elevation error $\left|d y_{e}\right|$ reaches level $10^{-4}$ and the middle point elevation error $\left|d y_{m}\right|$ reaches level $10^{-5}$, meaning that the E-M method has fast convergence rate and high precision.

It can be seen from Table 4 that the unstressed length and the elevation of point $j$ calculated by E-M method are symmetric with the middle point. It is mainly because the suspender forces are symmetric with the middle point. 


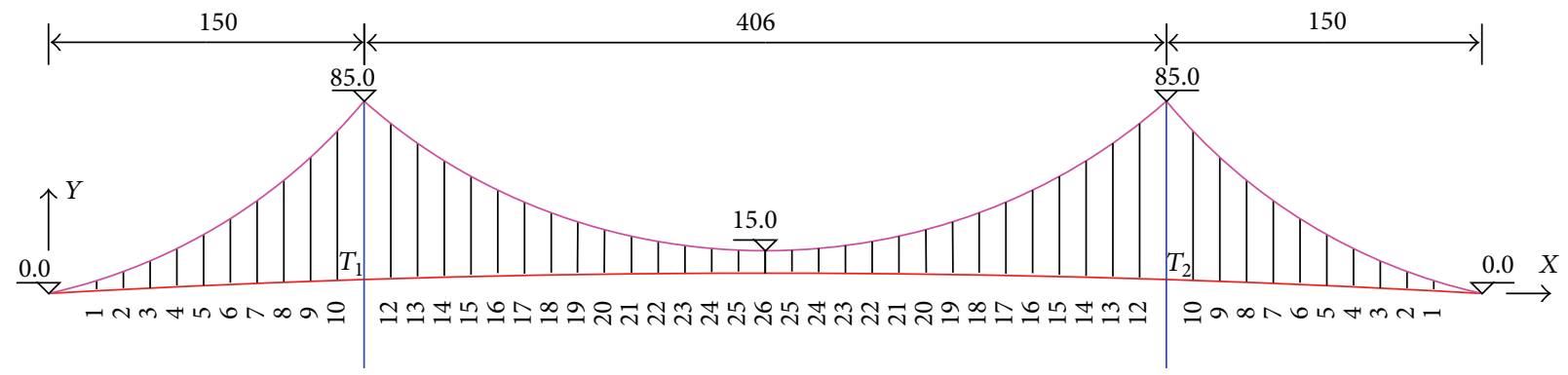

FIGURE 9: The general layout of a self-anchored suspension bridge.

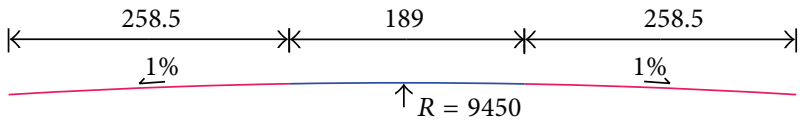

Figure 10: The design alignment of the stiffening girder (unit: $\mathrm{m}$ ).

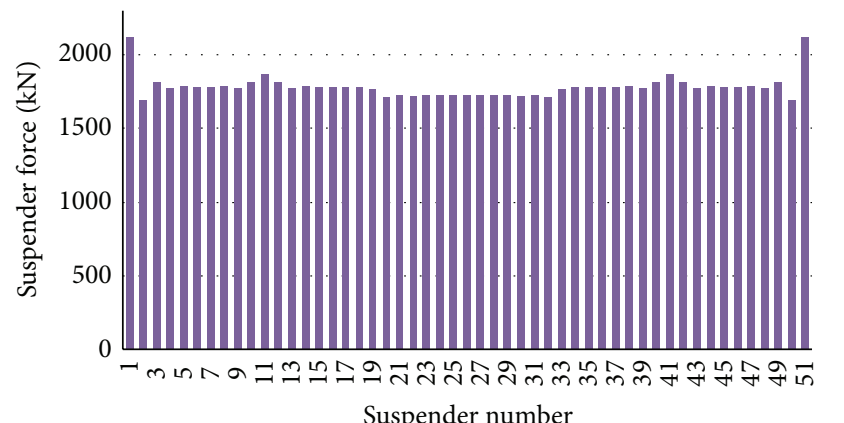

FIGURE 11: The distribution of the suspender force.

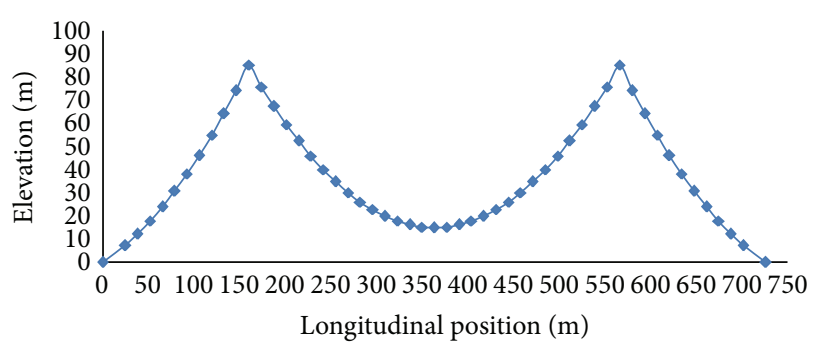

FIGURE 12: The alignment of the main cable.

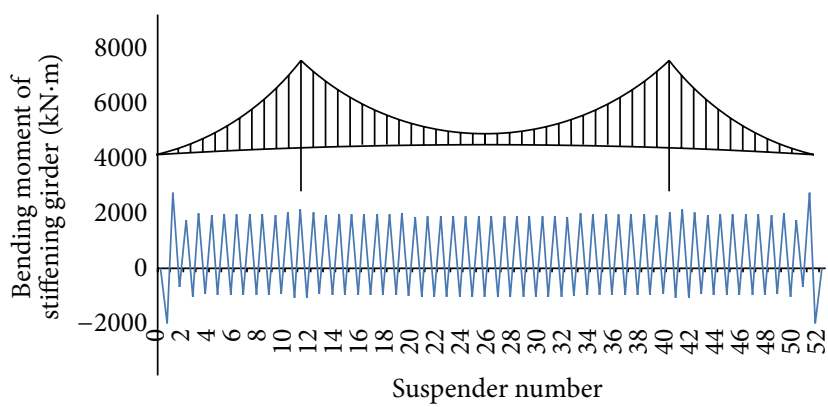

FIGURE 13: The bending moment diagram of the stiffening girder.
TABLE 2: The suspender forces.

\begin{tabular}{lc}
\hline Suspender number & Suspender force $(\mathrm{kN})$ \\
\hline 1 & 1798.0 \\
2 & 1798.6 \\
3 & 1799.4 \\
4 & 1800.2 \\
5 & 1800.9 \\
6 & 1801.6 \\
7 & 1802.3 \\
8 & 1803.1 \\
9 & 1802.3 \\
10 & 1801.6 \\
11 & 1800.9 \\
12 & 1800.2 \\
13 & 1799.4 \\
14 & 1798.6 \\
15 & 1798.0 \\
\hline
\end{tabular}

(ii) To verify the convergence of E-M method, the suspender forces in example 2 are distributed unevenly and asymmetrically, as shown in Table 5.

Table 6 indicates that although the suspender forces are distributed unevenly and asymmetrically, after 7 times of iteration like example 1 , the end point elevation error $\left|d y_{e}\right|$ reaches level $10^{-5}$ and the middle point elevation error $\left|d y_{m}\right|$ reaches level $10^{-5}$, which further proves that E-M method has good convergence and high reliability.

Table 7 and Figure 15 indicate that the main cable shape in example 1 is smooth mainly because the suspender forces are distributed evenly, while the main cable shape in example 2 is not smooth mainly because the suspender forces are distributed unevenly. In example 1 , the lowest point is $x=$ $108 \mathrm{~m}, y=-36 \mathrm{~m}$, while in example 2 the lowest point is $x=94.5 \mathrm{~m}, y=-39.56 \mathrm{~m}$ because the suspender force at $x=$ $94.5 \mathrm{~m}$ is $T_{7}=26802.3 \mathrm{kN}$. However, in either example 1 or 2, the shapes of the main cable all meet the requirements of three fixed-points, proving the high reliability of E-M method.

\section{Summaries and Conclusions}

For SSB, since the main cable is directly anchored on the stiffening girder, it is significant to consider the combined effects 
TABLE 3: Reaction of the main cable and the elevation error of the fixed point in each iteration step.

\begin{tabular}{lcccc}
\hline Iteration times & $H$ & $V$ & $\left|d y_{e}\right|$ & \\
\hline 1 & 43325.81 & 14448.82 & $1.58 E-02$ & $1.69 E+01$ \\
2 & 22983.66 & 14445.65 & $4.20 E-01$ & $1.48 E-01$ \\
3 & 22943.96 & 14400.96 & $3.90 E-01$ & $1.40 E-01$ \\
4 & 22978.93 & 14442.39 & $2.49 E-03$ & $1.24 E-03$ \\
5 & 22978.93 & 14442.12 & $1.37 E-03$ & $7.67 E-04$ \\
6 & 22978.88 & 14442.27 & $2.40 E-05$ & $1.00 E-05$ \\
7 & 22978.88 & 14442.27 & $1.30 E-05$ & $6.00 E-06$ \\
\hline
\end{tabular}

TABLE 4: The unstressed length and coordinates of the main cable.

\begin{tabular}{lccccc}
\hline Suspender number & Unstressed length $S(\mathrm{~m})$ & Elevation of point $j$ & Suspender number & Unstressed length $(\mathrm{m})$ & Elevation of point $j$ \\
\hline 1 & 15.90 & -8.45 & 9 & 13.50 & -35.45 \\
2 & 15.33 & -15.77 & 10 & 13.59 & -33.76 \\
3 & 14.83 & -21.96 & 11 & 13.77 & -30.95 \\
4 & 14.40 & -27.02 & 12 & 14.04 & -27.02 \\
5 & 14.04 & -30.95 & 13 & 14.40 & -21.96 \\
6 & 13.77 & -33.76 & 14 & 15.83 & -15.77 \\
7 & 13.59 & -35.45 & 15 & 15.90 & 0 \\
8
\end{tabular}

TABLE 5: The suspender forces.

\begin{tabular}{lc}
\hline Suspender number & Suspender force $(\mathrm{kN})$ \\
\hline 1 & 7800.0 \\
2 & 2350.7 \\
3 & 10.0 \\
4 & 9500.6 \\
5 & 556.3 \\
6 & 128.2 \\
7 & 26802.3 \\
8 & 803.1 \\
9 & 11.3 \\
10 & 68.2 \\
11 & 335.9 \\
12 & 98.2 \\
13 & 521.4 \\
14 & 6389.6 \\
15 & 788.0 \\
\hline
\end{tabular}

of the main cable, the suspender, and the stiffening girder. Concerning this issue, we focus on the theoretical researches and method improvements. The following conclusions can be drawn from this paper.

(i) An analytical calculation method considering the combined effect of the main cable-suspender-stiffening girder which cannot be solved in the existing methods is proposed in this paper. The method helps to understand the mechanical behavior of the whole structure in the preliminary design by a simpler model.
TABLE 6: Reaction of the main cable and the elevation error of the fixed point in each iteration step.

\begin{tabular}{lcccc}
\hline Iteration times & $H$ & $V$ & $\left|d y_{e}\right|$ & $\left|d y_{m}\right|$ \\
\hline 1 & 87063.86 & 29028.17 & $1.36 E+01$ & $2.16 E+01$ \\
2 & 51211.70 & 34492.46 & $1.85 E-01$ & $6.97 E-02$ \\
3 & 51179.04 & 34448.53 & $2.12 E-01$ & $7.56 E-02$ \\
4 & 51222.26 & 34498.76 & $3.74 E-04$ & $3.00 E-04$ \\
5 & 51222.42 & 34498.67 & $1.86 E-04$ & $1.86 E-04$ \\
6 & 51222.29 & 34498.72 & $3.00 E-06$ & $1.00 E-06$ \\
7 & 51222.29 & 34498.72 & $2.00 E-06$ & $1.00 E-06$ \\
\hline
\end{tabular}

(ii) Compared to the existing methods, in the proposed method, the main cable and the stiffening girder are all considered through the numerical analytical method, and the calculation procedure does not need to be iterated manually, which can simplify calculation process and save calculation time.

(iii) Using the proposed method, the reasonable finished bridge state satisfying the minimum strain energy theory of the stiffening girder can be obtained by ensuring zero vertical displacement of the hanging point under the joint action of the suspender force, the horizontal component of the main cable, and the dead load.

(iv) To verify the proposed method, examples are introduced, whose calculation results indicate that this method is reliable with fast convergence speed and high precision. The results can meet the precision requirements $\left(\delta=\Delta H / H<10^{-5}\right)$ with only 4 times of iteration and the calculated main cable shape is 
TABLE 7: The unstressed length and coordinates of the main cable.

\begin{tabular}{lccccc}
\hline Suspender number & Unstressed length $S(\mathrm{~m})$ & Elevation of point $j$ & Suspender number & Unstressed length $(\mathrm{m})$ & Elevation of point $j$ \\
\hline 1 & 16.22 & -9.07 & 9 & 13.99 & -32.18 \\
2 & 15.16 & -16.06 & 10 & 14.00 & -28.34 \\
3 & 14.87 & -22.39 & 11 & 14.01 & -24.45 \\
4 & 14.86 & -28.69 & 12 & 14.05 & -20.44 \\
5 & 13.98 & -32.45 & 13 & 14.06 & -16.37 \\
6 & 13.93 & -36.04 & 14 & 14.71 & -12.14 \\
7 & 13.92 & -39.56 & 15 & 14.81 & -6.19 \\
8
\end{tabular}

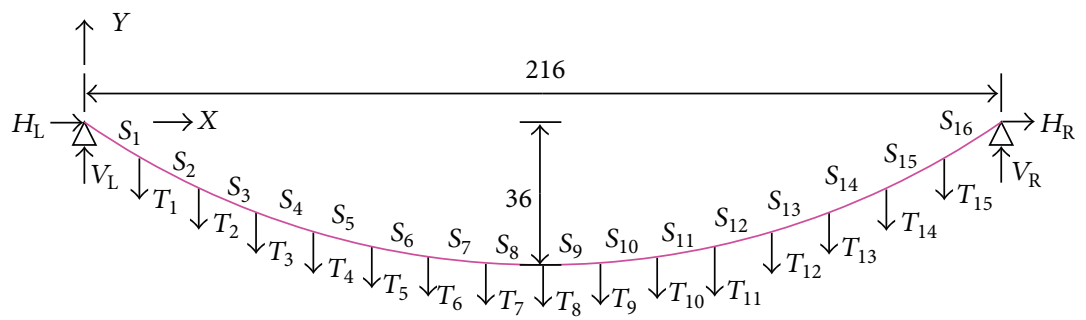

FIgURE 14: The calculation schematic of the main cable of a suspension bridge.

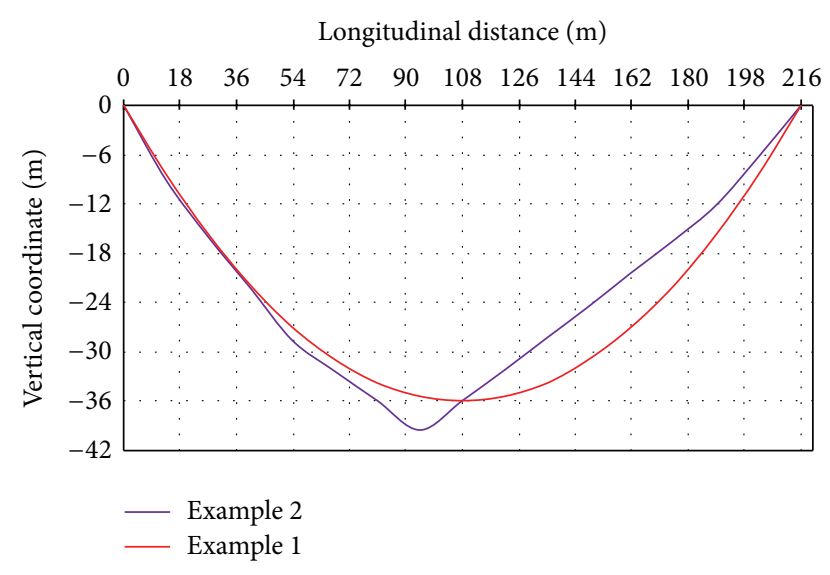

FIGURE 15: The calculation schematic of the main cable segment.

smooth. The suspender force and the internal force of the stiffening girder are relatively uniform.

(v) The E-M iteration method in Part II considers the elevation requirements of both the ending points and intermediate points and ensures the convergence during the iteration by improving the iteration equation of $d H$ and $d V$.

Consequently, we expect that the proposed analytical calculation method will provide a brand new way for designers in the SSB preliminary design.

\section{Conflict of Interests}

The authors declare that there is no conflict of interests regarding the publication of this paper.

\section{Acknowledgments}

The research is supported by National Basic Research Program of China (2012CB723300) and Natural Science Foundation Project of CQ (CSTC2012jjB0118). The authors also would like to thank Ministry of Transport of China (MOT) for funding of the present research (2010-353-341-230).

\section{References}

[1] D. B. Steinman, A Practical Treatise on Suspension Bridges, Wiley, New York, NY, USA, 1953.

[2] A. Jennings, "Deflection theory analysis of different cable profiles for suspension bridges," Engineering Structures, vol. 9, no. 2, pp. 84-94, 1987.

[3] G. P. Wollmann, "Preliminary analysis of suspension bridges," Journal of Bridge Engineering, vol. 6, no. 4, pp. 227-233, 2001.

[4] H. Ohshima, K. Sato, and N. Watanabe, "Structural analysis of suspension bridges," Journal of Engineering Mechanics, vol. 110, no. 3, pp. 392-404, 1984.

[5] M.-R. Jung, D.-J. Min, and M.-Y. Kim, "Nonlinear analysis methods based on the unstrained element length for determining initial shaping of suspension bridges under dead loads," Computers and Structures, vol. 128, pp. 272-285, 2013.

[6] A. Montoya, R. Betti, G. Deodatis, and H. Waisman, "A stochastic finite element approach to determine the safety of suspension bridge cables," in Proceedings of the ASCE International Workshop on Computing in Civil Engineering (IWCCE '13), pp. 1-8, June 2013.

[7] H.-K. Kim, M.-J. Lee, and S.-P. Chang, "Determination of hanger installation procedure for a self-anchored suspension bridge," Engineering Structures, vol. 28, no. 7, pp. 959-976, 2006.

[8] H.-K. Kim, M.-J. Lee, and S.-P. Chang, "Non-linear shapefinding analysis of a self-anchored suspension bridge," Engineering Structures, vol. 24, no. 12, pp. 1547-1559, 2002. 
[9] D.-L. Tan, "Decision method on reasonable design state of selfanchored suspension bridge," China Journal of Highway and Transport, vol. 18, no. 2, pp. 51-55, 2005 (Chinese).

[10] Y. Han, Z.-Q. Chen, and S.-D. Luo, Calculation Method on Shape Finding of Self-Anchored Suspension Bridge with Spatial Cables, Changsha University of Science \& Technology, Changsha, China, 2009.

[11] C.-X. Li, H.-J. Ke, H.-B. Liu, and G.-Y. Xia, "Determination of finished bridge state of self-anchored suspension bridge with spatial cables," Engineering Mechanics, vol. 27, no. 5, pp. 137-146, 2010.

[12] L. Greco, N. Impollonia, and M. Cuomo, "A procedure for the static analysis of cable structures following elastic catenary theory," International Journal of Solids and Structures, vol. 51, no. 7-8, pp. 1521-1533, 2014.

[13] A. Andreu, L. Gil, and P. Roca, "A new deformable catenary element for the analysis of cable net structures," Computers and Structures, vol. 84, no. 29-30, pp. 1882-1890, 2006.

[14] W. Paulsen and G. Slayton, "Eigenfrequency analysis of cable structures with inclined cables," Applied Mathematics and Mechanics, vol. 27, no. 1, pp. 37-49, 2006.

[15] J. A. Ochsendorf and D. P. Billington, "Self-anchored suspension bridges," Journal of Bridge Engineering, vol. 4, no. 3, pp. 151156, 1999.

[16] M. S. A. Abad, A. Shooshtari, V. Esmaeili, and A. N. Riabi, "Nonlinear analysis of cable structures under general loadings," Finite Elements in Analysis and Design, vol. 73, pp. 11-19, 2013.

[17] H.-T. Thai and S.-E. Kim, "Nonlinear static and dynamic analysis of cable structures," Finite Elements in Analysis and Design, vol. 47, no. 3, pp. 237-246, 2011.

[18] M.-Y. Kim, D.-Y. Kim, M.-R. Jung, and M. M. Attard, "Improved methods for determining the 3 dimensional initial shapes of cable-supported bridges," International Journal of Steel Structures, vol. 14, no. 1, pp. 83-102, 2014.

[19] R. Karoumi, "Some modeling aspects in the nonlinear finite element analysis of cable supported bridges," Computers and Structures, vol. 71, no. 4, pp. 397-412, 1999. 


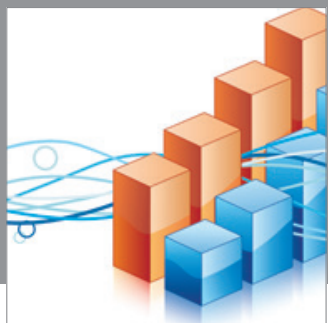

Advances in

Operations Research

mansans

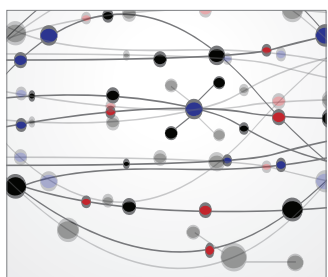

The Scientific World Journal
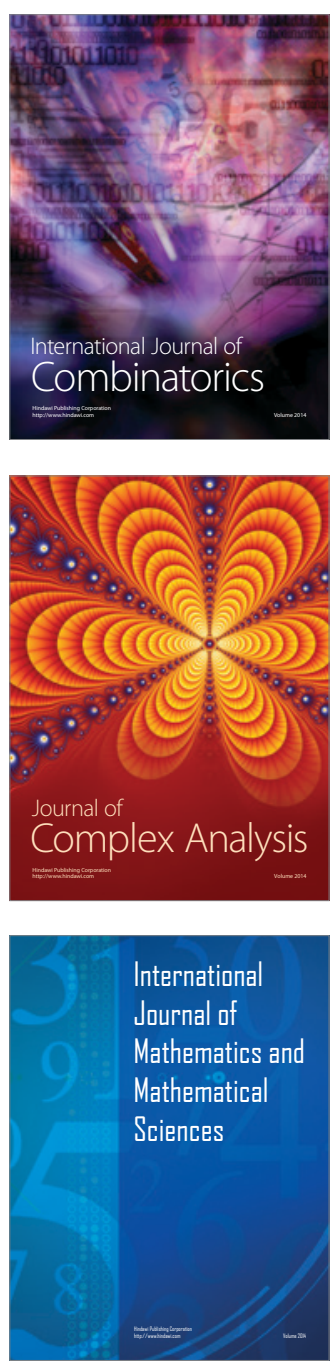
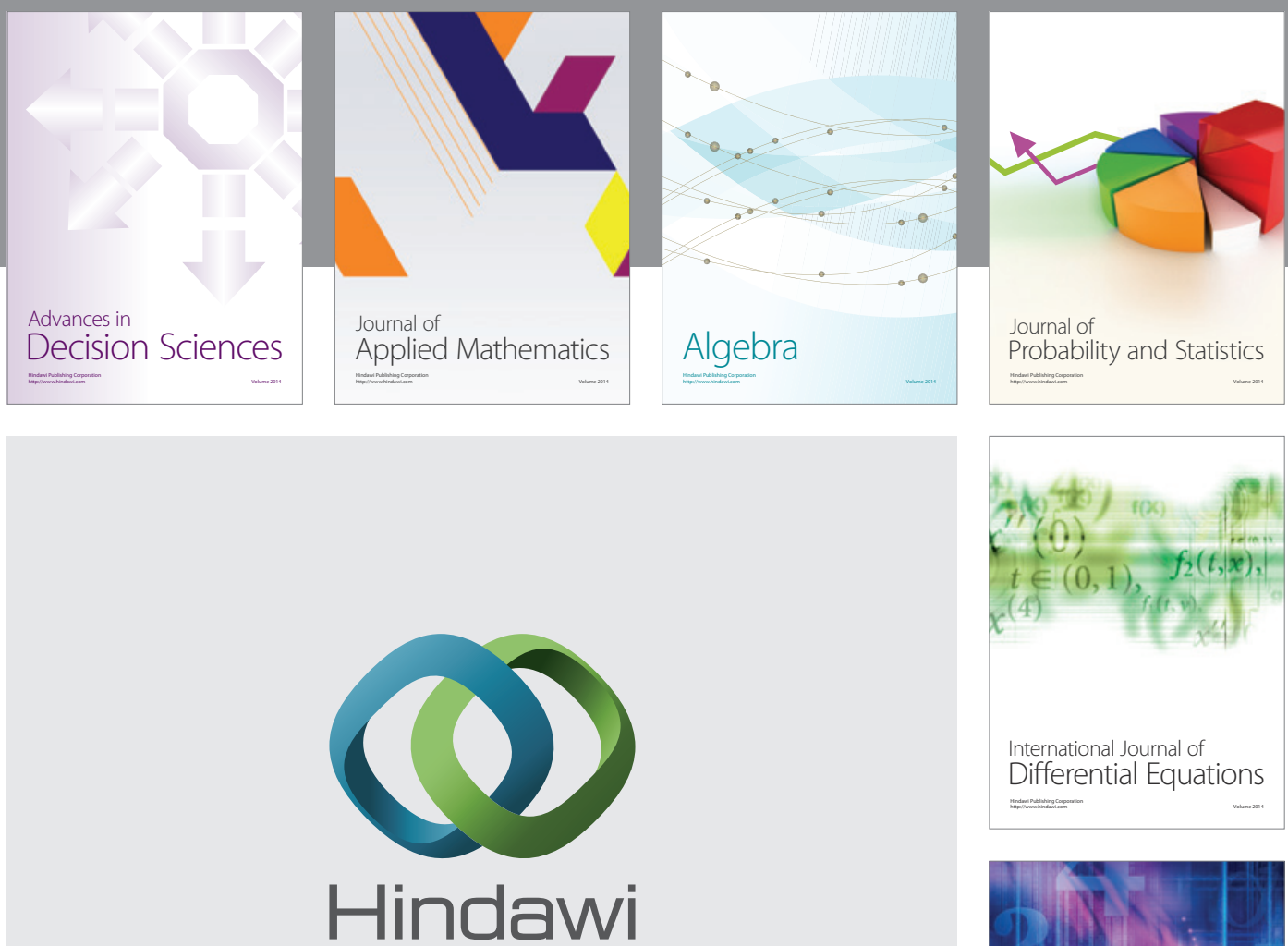

Submit your manuscripts at http://www.hindawi.com
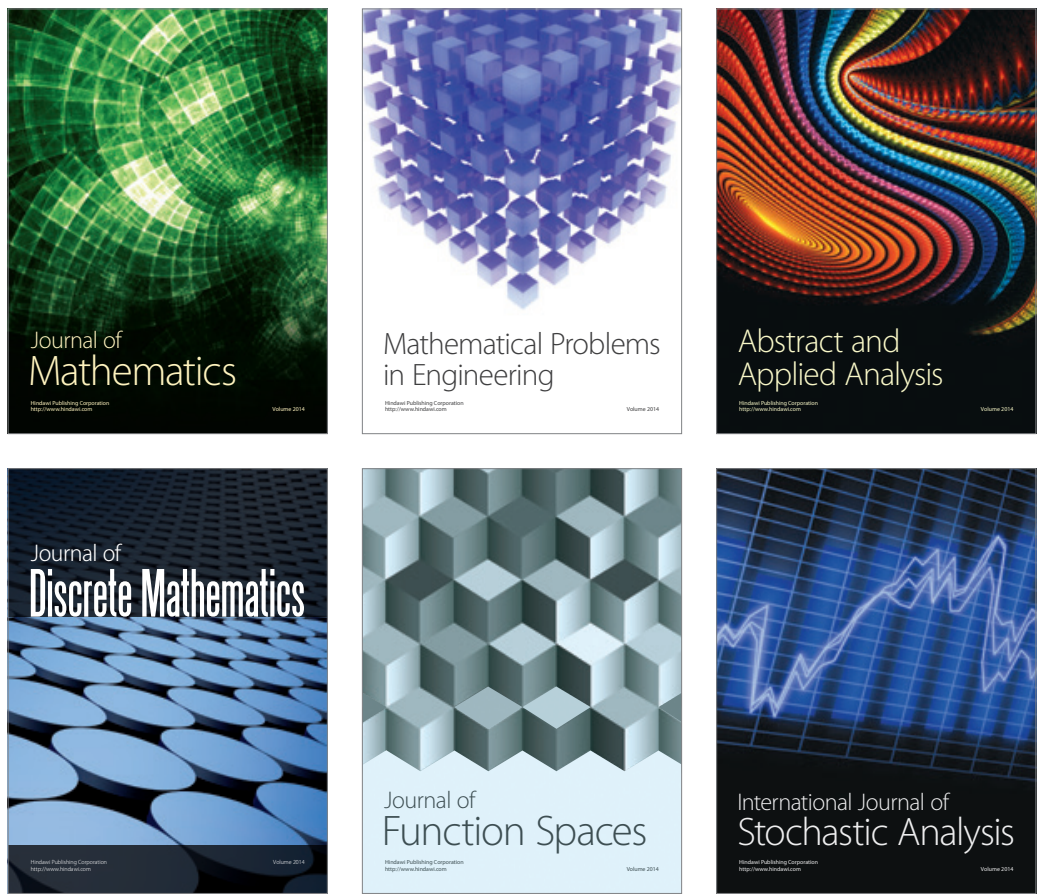

Journal of

Function Spaces

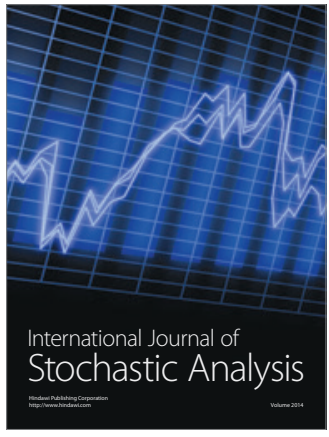

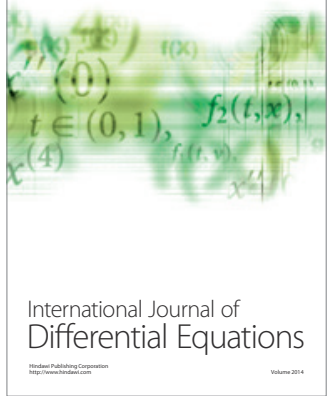
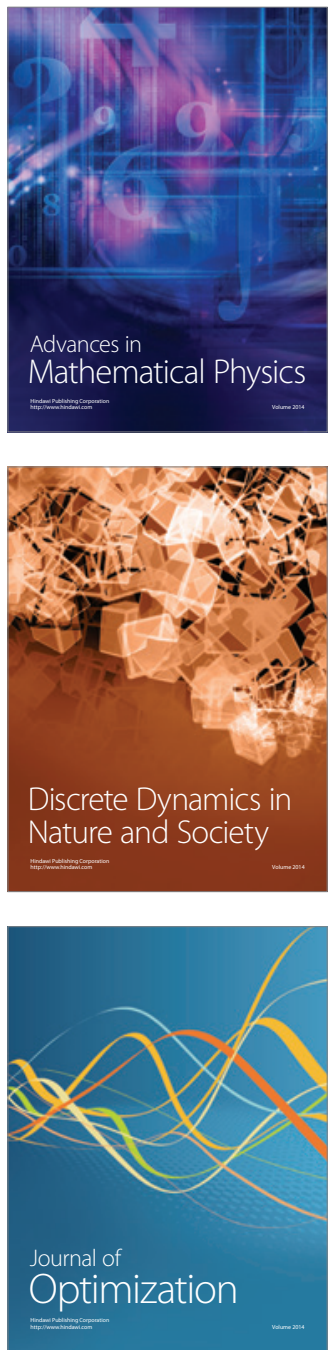